\title{
Percutaneous Cell Delivery Into the Heart Using Hydrogels Polymerizing In Situ
}

\author{
Timothy P. Martens ${ }^{\star}, \dagger$, Amandine F. G. Godier ${ }^{\star}$, Jonathan J. Parks ${ }^{\star}$, Leo Q. Wan ${ }^{\star}$, Michael S. \\ Koeckert ${ }^{*}$, George M. Eng ${ }^{\star}$, Barry I. Hudson ${ }^{\dagger}$, Warren Sherman ${ }^{\ddagger}$, and Gordana Vunjak- \\ Novakovic \\ *Department of Biomedical Engineering, Columbia University, New York, NY, USA \\ tDepartment of Surgery, Columbia University Medical Center, New York, NY, USA \\ ${ }^{\ddagger}$ Center for Interventional Vascular Therapy, Columbia University Medical Center, New York, NY, \\ USA
}

\begin{abstract}
Heart disease is the leading cause of death in the US. Following an acute myocardial infarction, a fibrous, noncontractile scar develops, and results in congestive heart failure in more than 500,000 patients in the US each year. Muscle regeneration and the induction of new vascular growth to treat ischemic disorders of the heart can have significant therapeutic implications. Early studies in patients with chronic ischemic SLVD using skeletal myoblasts or bone marrow-derived cells report improvement in left ventricular ejection function (LVEF) and clinical status, without notable safety issues. Nonetheless, the efficacy of cell transfer for cardiovascular disease is not established, in part due to a lack of control over cell retention, survival, and function following delivery. We studied the use of biocompatible hydrogels polymerizable in situ as a cell delivery vehicle, to improve cell retention, survival, and function following delivery into the ischemic myocardium. The study was conducted using human bone marrow-derived mesenchymal stem cells and fibrin glue, but the methods are applicable to any human stem cells (adult or embryonic) and a wide range of hydrogels. We first evaluated the utility of several commercially available percutaneous catheters for delivery of viscous cell/hydrogel suspensions. Next we characterized the polymerization kinetics of fibrin glue solutions to define the ranges of concentrations compatible with catheter delivery. We then demonstrate the in vivo effectiveness of this preparation and its ability to increase cell retention and survival in a nude rat model of myocardial infarction.
\end{abstract}

\section{Keywords}

Hydrogel; uman stem cells; Heart repair

\section{INTRODUCTION}

Congestive heart failure (CHF) is an enormous health problem in the US, affecting nearly 5 million people ( 0.5 million newly diagnosed/year) and imposing a significant burden on those

Copyright (C) 2009 Cognizant Comm. Corp.

Address correspondence to Timothy P. Martens, M.D., Department of Surgery, Columbia University Medical Center, 177 Fort Washington Ave., MHB 7-435, New York, NY 10032, USA. Tel: (212) 305-5755; Fax: (212) 305-533; tpm2102@ columbia.edu or Gordana Vunjak-Novakovic, Ph.D., Professor, Department of Biomedical Engineering, Columbia University, Vanderbilt Clinic 12th floor, Room 12-234, 622 West 168th Street, New York, NY 10032, USA. Tel: (212) 305-2304, Fax: (212) 305-4692;

gv2131@columbia.edu. 
afflicted (12-15 million office visits, 6.5 million hospital days, and almost 0.3 million deaths/ year) that is surely to increase as the population ages (7). While cardiac transplantation remains the definitive treatment for end-stage heart failure, it is seriously limited by a scarcity of available donor organs. Alternative approaches such as cell-based therapies have therefore garnered much attention in recent years. Early cell therapy studies utilized skeletal myoblasts (12) or bone marrow-derived stem cells (11) with or without concomitant revascularization. These studies demonstrated modest gains in left ventricular ejection fraction (LVEF) and clinical status, along with excellent safety profiles of cell injection techniques (15). However, the efficacy of cell-based procedures has not been well established, in part due to a lack of control over cell retention, survival, and function following delivery.

The key limitation of all existing modalities of cell delivery is the massive cell loss that occurs within a very short time and, irrespective of cell type or formulation, delivery technique and disease state. Estimates for acute retention vary depending upon route of delivery but are uniformly poor $(5,9)$. For instance, in an elegant study utilizing radio-labeled bone marrow mononuclear cells (6), only $11 \pm 3 \%$ of cells remained in the heart just 90 min after intramyocardial injection. Retention rates for intracoronary $(2.6 \pm 0.3 \%)$ and retrograde venous delivery $(3.2 \pm 1.0 \%)$ were even lower. All three methods were associated with rapid redistribution of the cells delivered into the heart to the lungs, liver, spleen, and other organs throughout the body. Postulated mechanisms for poor retention include inadvertent intravascular delivery to coronary veins and venules, rapid interstitial clearance by lymphatics, and direct leakage of cell suspension once the needle is removed.

In addition, the local environment presents an untenable milieu for freshly implanted cells following both acute (inflammation) and chronic (fibrosis) myocardial infarction (14). The infarct bed is poorly oxygenated, contains dead and apoptotic cells, and has a progressively increasing stiffness, a combination of features that does not support the viability and well-being of implanted cells. This additional limitation of delivering "naked" cells has prompted research towards multiple other modalities for cell delivery-from the use of biomaterials as cell delivery vehicles (4) to engineering a contractile cardiac "patch" containing the repair cells (10).

Intramyocardial in situ polymerization of polymers in form of a hydrogel represents one possible solution to address both leakage and clearance-mediated cell loss, and the need for "conditioning" of the immediate cell environment. There are a number of biocompatible hydrogels, polymerizing in response to chemical, thermal, or optical triggers, including fibrin (1), alginate (8), and polyethylene glycol-based systems (2). Fibrin glue is a hydrogel widely used in surgery, cell culture, and tissue engineering that consists of a two-component system. Fibrinogen monomers (component A) are dissolved in a liquid carrier such as saline. Exposure of fibrinogen monomers to thrombin (component B) results in conversion of fibrinogen to fibrin, which polymerizes to form a fibrin mesh, by mechanisms similar to those involved in normal clotting in vivo. Both autologous and recombinant off-the-shelf fibrin glue preparations are available, and have seen extensive use as procoagulants during cardiac and other surgery. Additionally, preclinical literature supports an angiogenic role for fibrin glue following myocardial ischemia in rats, making this an attractive system for possible catheter-based cell therapy of the heart (3).

Cell delivery to the heart is being performed by surgical and catheter-based (percutanous) methods. Catheter-based cell delivery has several advantages over direct surgical injection: 1) lower procedure risk, 2) high potential for integration into clinical practice, and 3) more suitability for repeat applications compared to surgery. For these reasons, the majority of current cardiac cell therapy trials employ a percutaneous delivery method, the most common type of which is endoventricular or transendocardial injection (13). 
However, the use of intramyocardial injection catheters also imposes significant design constraints on a cell/hydrogel preparation (Fig. 1). First, the long internal lumen of the catheter imposes a high resistance to flow that in turn limits the maximum viscosity of the injectate. Second, because current catheters employ a single injection lumen, the fibrin glue components must be mixed prior to injection, resulting in a time-dependant increase in viscosity of cell/ hydrogel suspension. A successful formulation must therefore polymerize quickly enough to improve cell retention, yet slowly enough to allow adequate time for injection site selection, catheter positioning, and delivery.

In this article we first assess the utility of several commercially available percutaneous catheters using standards of solutions with known viscosity to determine a working limit for this parameter. Next we characterize the polymerization kinetics of different fibrin glue solutions to define the ranges of parameters compatible with catheter delivery. We then demonstrate the in vitro and in vivo effectiveness of this preparation, and its ability to increase cell retention and prevent redistribution of delivered product in an animal model of myocardial infarction.

\section{MATERIALS AND METHODS}

\section{Viscosity Limit of Clinically Available Catheters}

A system for rheological measurements with constant fluid pressure was established, whereby a solution was pushed through each of the catheters tested at a constant flow velocity. Dextran solutions of known viscosity (Sigma, at 5\%, 10\%, 20\%, 25\% w/v) were passed through catheters and the ease with which the solution flowed was characterized as "easily delivered" (+), "low flow" (LF), or "no flow" (NF). Viscosities of each dextran solution were then confirmed using an ARES-LS1 Rheometer (TI Instruments), using cone-and-plate configuration with diameter of $5 \mathrm{~cm}$, and angular displacement of 0.01 radians at $1 \mathrm{~Hz}$.

\section{Time-Dependent Viscosity Profiles}

Bovine fibrinogen (Sigma) was dissolved in PBS to yield 1\%, 2\%, 5\%, 10\%, and 15\% (w/v) solutions. Each of these solutions was loaded into the cone-and-plate configured Ares-LS1 Rheometer (TA instruments). Thrombin (Sigma T6200) was reconstituted to a concentration of $100 \mathrm{U} / \mathrm{ml}$. Diluted thrombin, $50 \mathrm{U} / \mathrm{ml}$ and $20 \mathrm{U} / \mathrm{ml}$, was combined with fibrinogen at a concentration of $2 \%, 5 \%$, or $10 \% \mathrm{w} / \mathrm{v}$ to initiate polymerization to fibrin glue.

\section{Cell Viability in Fibrin}

To obtain human mesenchymal stem cells (hMSCs), human bone marrow mononuclear cells (LONZA 2M-125) were plated in T75 flasks and cultured in DMEM (Gibco, \#12430) with $10 \%$ FBS (Gibco, \#26140). The adherent cells were expanded to the fourth passage for use in all subsequent experiments. hMSCs were encapsulated in fibrin gels at a density of $4 \times 10^{6}$ cells $/ \mathrm{cm}^{3}$.

Fibrin gels were fabricated by combining $2 \%$ w/v fibrinogen with $20 \mathrm{U} / \mathrm{ml}$ thrombin in a 96well plate. At time points of $0.5,24$, and $72 \mathrm{~h}$ after gel fabrication, gels were stained with LIVE/ DEAD Invitrogen L-3224 and digital images obtained from a fluorescent microscope. Images were then analyzed in Matlab using codes written to allow automated unbiased counting of red (dead) and green (live) hMSCs.

\section{Scanning Electron Microscopy}

Fibrinogen from bovine serum was dissolved to $2 \%(\mathrm{w} / \mathrm{v})$ solution and polymerized with 50 $\mathrm{U} / \mathrm{ml}$ thrombin to produce $500 \mu \mathrm{l}$ volume aliquots of hydrogels. Hydrogels were placed in sterile water, submerged in liquid nitrogen, freeze-dried using a lyophilizer (Labconco 7740020), and sputtered-coated with $10 \mathrm{~nm}$ gold-palladium in a Denton Desktop-2 sputtering 
system. Samples were then mounted onto carbon tape and imaged in Hitachi 4700 Scanning Electron Microscope at a range of magnifications between 20 and 1000x and digitally stored.

\section{Animal Model and Quantification of Retention}

Rowett (rnu/rnu) athymic nude rats (Harlan Sprague-Dawley) were used in studies approved by the Columbia University Institutional Animal Care and Use Committee (IACUC). Rats were anesthetized with inhalation of isoflurane (2-3\%), endotracheally intubated, and mechanically ventilated. The heart was exposed through a left thoracotomy and the pericardium incised. The LAD was then ligated with 7-0 prolene suture $2-3 \mathrm{~mm}$ below the edge of the left atrium. Confluent T75 flasks of fourth passage hMSCs were incubated overnight with $10 \mu \mathrm{l}$ of iridium colloid label (Biopal, CL-300G02-1) prior to injection. Aliquots of 500,000 labeled hMSCs were suspended either in $300 \mu$ of PBS $(n=6)$ or a $300-\mu$ l mixture of fibrin glue $(2 \%$ w/v fibrinogen, $20 \mathrm{U} / \mathrm{ml}$ thrombin, $n=6$ ) and immediately injected into the border zone in two divided injections of $150 \mu \mathrm{l}$ each. Ninety minutes after cell injection, the rats were euthanized and the heart, lungs, liver, kidneys, and spleen were recovered. Tissue specimens were dehydrated and sent to Biopal for neutron beam bombardment and quantification according to the manufacturer's protocol.

\section{Quantitative PCR Analysis}

Total RNA was isolated by lysing freshly pelleted cells by an RNAqueous isolation kit (Ambion \#AM1912). DNA contamination was enzymatically removed (Turbo DNAse, Ambion) and $1 \mu \mathrm{g}$ of total RNA was used to build a cDNA library with the Reaction Ready cDNA Synthesis kit (Superarray Bioscience Corporation) and a Biorad MyCycler according to the manufacturer's specification. Custom RT2Profiler PCR Arrays (Superarray Bioscience Corporation, cat. \#CAPH-0154B) were then run on a Stratagene MX-3005 cycler according to the manufacturer's protocol and analyzed with MxPro v3.0 software. Fold changes were expressed using the $\Delta \Delta \mathrm{Ct}$ method with normalization of the raw data to the GAPDH housekeeper.

\section{Statistical Analysis}

All averages are reported as mean \pm SD. For comparison between fibrin and saline suspended cells, a two-tailed Student's $t$-test was used with $p<0.05$ considered significant.

\section{RESULTS}

Given the importance of hydrogel flow properties for catheter-based delivery of cell/hydrogel suspensions, we first specified the range of hydrogel viscosity that is compatible with the use of a catheter. Hydrogel preparations were formed by utilizing dextran-based standards, to obtain a series of solutions with a gradually increasing viscosity. Four different catheter types with a wide range of path lengths $(115-177.5 \mathrm{~cm})$ and inner diameters $(0.19-0.43 \mathrm{~mm})$ were used in these rheological studies. Table 1 summarizes these studies. Dextran solutions with concentrations less than $5 \% \mathrm{w} / \mathrm{v}$ (viscosity of $\leq 9.39 \mathrm{cP}$ ) were easily passed through all four catheters. All catheters except for the one with the longest and most narrow lumen (catheter D) handled the $10 \%$ dextran solution (viscosity of $30.8 \mathrm{cP}$ ) with ease. Injection of $20 \%$ dextran solutions (viscosity of $121 \mathrm{cP}$ ) was possible through catheters A, B, and C, but significantly more force was required compared to less viscous solutions to produce forward flow. Only the catheter with the shortest path length (catheter C) was able to pass $25 \%$ dextran solutions (231 cP). From these tests we estimated an operational viscosity upper limit in the $150-200 \mathrm{cP}$ range.

Next we analyzed the starting viscosity of fibrinogen suspended in saline prior to addition of thrombin and initiation of polymerization (Fig. 2a). Fibrinogen solutions demonstrated a nonlinear increase in viscosity; however, all solutions tested were well under the established 
upper limit of $200 \mathrm{cP}$. Above fibrinogen concentrations of $15 \%$, visible clumping occurred and could only be overcome by elevating the temperature of the mixture well above body temperature. Having now established acceptable starting concentrations of fibrinogen $(<15 \%$ $\mathrm{w} / \mathrm{v}$ ) we characterized the time-dependent changes in viscosity associated with addition of thrombin and polymerization of fibrin monomers (Fig. 2b). Early testing with higher fibrinogen concentrations $(>10 \% \mathrm{w} / \mathrm{v})$ was associated with rapid polymerization that was incompatible with percutaneous delivery. In contrast, by decreasing the starting concentrations of fibrinogen to $5 \%$ and of thrombin to $20 \mathrm{U} / \mathrm{ml}$, injection windows in the 6-8 min range could be achieved. Of note, fibrin glue preps crossing the $200 \mathrm{cP}$ limit could be easily cleared from catheter $\mathrm{C}$ by manual flushing with saline, enabling reuse of the catheter with freshly mixed fibrin glue.

To characterize the biocompatibility of fibrin glue, we encapsulated fourth passage mesenchymal stem cells in $2 \% \mathrm{w} / \mathrm{v}$ gels polymerized with $20 \mathrm{U} / \mathrm{ml}$ of thrombin. This preparation demonstrated excellent long-term viability (Fig. 3a) and normal morphology (Fig. $3 b$ ) over $72 \mathrm{~h}$ of culture with hMSCs maintaining $>90 \%$ viability at all time points. After 72 h, hydrogels were lyophilized for scanning electron microscopy (SEM), which demonstrated pore sizes in the $20-40 \mathrm{~mm}$ range (Fig. 3c) and a somewhat homogenous architecture (Fig. 3d). RT-PCR analysis of several hMSC markers including $\alpha$-smooth muscle actin and connexin-43 showed no significant change in expression after $72 \mathrm{~h}$ of culture in fibrin glue (data not shown).

Having established acceptable parameters for percutaneous application, we tested the in vivo effectiveness of intracardiac polymerization of fibrin glue in a rat model of acute myocardial infarction. Early attempts to inject hydrogel via a 23 -gauge needle resulted in excessive bleeding. After the needle size was reduced to 26 gauge $5 / 8$ in., successful delivery of a $2 \%$ $\mathrm{w} / \mathrm{v}$ fibrinogen $/ 20 \mathrm{U} / \mathrm{ml}$ thrombin preparation was achieved with reproducible results. Intracardiac injection of this preparation resulted in a visible blanching of the anterior wall with no appreciable loss of injectate from the injection site (Fig. 4a). Ten days postinjection the anterior wall demonstrated visible retention of polymerized fibrin grossly (Fig. 4b, c) and histologically (Fig. 4d).

To quantify the effect of in situ polymerization of fibrin glue on cell retention and redistribution, we next suspended 500,000 iridium-labeled hMSCs in either saline or fibrin glue ( $2 \% \mathrm{w} / \mathrm{v}$ fibrinogen, $20 \mathrm{U} / \mathrm{ml}$ thrombin) and delivered them into acutely infarcted nude rats via two separate $150-\mu \mathrm{l}$ injections. Ninety minutes after cell delivery, the rats were sacrificed and the hearts and remote organs procured for quantification of retained cells (Fig. 4e). There was no significant difference in the total number of hMSCs recovered from the heart and remote organs $\left(3.31 \pm 1.39 \times 10^{5}\right.$ vs. $3.41 \pm 1.00 \times 10^{5}$, fibrin glue vs. saline). Delivery of hMSCs in fibrin glue was associated with a substantial increase in local cardiac retention $(39.7 \pm 7.0 \%$ vs. 22.6 $\pm 3.5 \%$ of recovered cells, $p<0.05)$ as well as a significant reduction in redistribution to the liver $(21.7 \pm 7.9 \%$ vs. $41.7 \pm 0.4 \%, p<0.05)$ and kidney $(0.3 \pm 0.3 \%$ vs. $8.9 \pm 8.8 \%, p<0.05)$. Interestingly, redistribution of hMSCs to the lungs was not statistically different for the two methods $(38.3 \pm 14.6 \%$ vs. $23.9 \pm 9.3 \%)$.

\section{DISCUSSION}

Heart failure following acute and chronic myocardial infarction remains a therapeutic challenge with gradual progression of disease and functional decline leading to death being the most common outcome. Various modalities of cell delivery have gained a lot of attention in recent years. While early clinical trial results were very promising, larger randomized trials have produced conflicting data, sometimes with similar cell types showing sometimes positive and sometimes negative results. This lack of convincing evidence for the efficacy of delivered cells may due to differences in cell processing, delivery methods, and timing of administration, such 
that poor cell retention and engraftment remain a central problem common to all cell types and routes of administration.

In this study, we have demonstrated that by controlling the composition of fibrinogen and thrombin components, a fibrin-based hydrogel can be prepared that is compatible with current percutaneous injection catheters. This hydrogel can be delivered under clinically relevant conditions (point of care component mixing, 10-min injection window) and greatly enhances local retention of injected cells in the heart as well as prevents their redistribution to distance organs. Furthermore, the system and parameters developed here are applicable to all cell types and may represent an enabling technology capable of improving current cell delivery techniques.

While some of the currently available catheters were suitable for cell/hydrogel delivery, a number of avenues for design improvement exists. First, given that the device with shortest path length and largest internal luminal diameter performed best, increasing the inner diameter even slightly may result in broadening the injection window by raising the upper limit of passable viscosity. Second, a double-lumen system that keeps the fibrinogen and thrombin components isolated until they reached the target tissue would potentially relieve the timing constraints associated with intracatheter polymerization altogether.

As this was only an initial pilot study, more robust functional studies should be undertaken to determine if the retention and distribution benefit demonstrated here results in greater functional recovery. The technique should also be applied to other cell types to confirm its broader potential. Alternative hydrogel systems are also available, allowing for the possibility of matching cell types to hydrogel compositions. Further functionalization of these hydrogels through growth factor tethering or backbone modification may result in even greater benefit and should be explored.

\section{Acknowledgments}

Funding for this work was provided in part by R01 HL076485 (to G.V.-N., supplement to A.F.G.G.).

\section{REFERENCES}

1. Ahmed T, Dare E, Hincke M. Fibrin: A versatile scaffold for tissue engineering applications. Tissue Eng. Part B Rev 2008;14(2):199-215. [PubMed: 18544016]

2. Bjugstad K, Redmond DJ, Lampe K, Kern D, Sladek JJ, Mahoney M. Biocompatibility of PEG-based hydrogels in primate brain. Cell Transplant 2008;17(4):409-415. [PubMed: 18522243]

3. Christman KL, Vardanian AJ, Fang Q, Sievers RE, Fok HH, Lee RJ. Injectable fibrin scaffold improves cell transplant survival, reduces infarct expansion, and induces neovasculature formation in ischemic myocardium. J. Am. Coll. Cardiol 2004;44(3):654-660. [PubMed: 15358036]

4. Ferreira LS, Gerecht S, Fuller J, Shieh HF, Vunjak-Novakovic G, Langer R. Bioactive hydrogel scaffolds for controllable vascular differentiation of human embryonic stem cells. Biomaterials 2007;28(17):2706-2717. [PubMed: 17346788]

5. Hayashi M, Li TS, Ito H, Mikamo A, Hamano K. Comparison of intramyocardial and intravenous routes of delivering bone marrow cells for the treatment of ischemic heart disease: An experimental study. Cell Transplant 2004;13(6):639-647. [PubMed: 15648734]

6. Hou D, Youssef EA-S, Brinton TJ, Zhang P, Rogers P, Price ET, Yeung AC, Johnstone BH, Yock PG, March KL. Radiolabeled cell distribution after intramyocardial, intracoronary, and interstitial retrograde coronary venous delivery: Implications for current clinical trials. Circulation 2005;112(9 Suppl):I-150-156. [PubMed: 16159808]

7. Hunt SA, Haddad F. The changing face of heart transplantation. J. Am. Coll. Cardiol 2008;52(8):587598. [PubMed: 18702960] 
8. Kong HJ, Mooney DJ. The effects of poly(ethyleneimine) (PEI) molecular weight on reinforcement of alginate hydrogels. Cell Transplant 2003;12(7):779-785. [PubMed: 14653624]

9. Perin EC, Silva GV, Assad JAR, Vela D, Buja LM, Sousa ALS, Litovsky S, Lin J, Vaughn WK, Coulter S, Fernandes MR, Willerson JT. Comparison of intracoronary and transendocardial delivery of allogeneic mesenchymal cells in a canine model of acute myocardial infarction. J. Mol. Cell. Cardiol 2008;44(3):486-495. [PubMed: 18061611]

10. Radisic M, Park H, Shing H, Consi T, Schoen FJ, Langer R, Freed LE, Vunjak-Novakovic G. From the cover: Functional assembly of engineered myocardium by electrical stimulation of cardiac myocytes cultured on scaffolds. Proc. Natl. Acad. Sci. USA 2004;101(52):18129-18134. [PubMed: 15604141]

11. Schächinger V, Assmus B, Britten MB, Honold J, Lehmann R, Teupe C, Abolmaali ND, Vogl TJ, Hofmann W-K, Martin H, Dimmeler S, Zeiher AM. Transplantation of progenitor cells and regeneration enhancement in acute myocardial infarction: Final one-year results of the TOPCAREAMI Trial. J. Am. Coll. Cardiol 2004;44(8):1690-1699. [PubMed: 15489105]

12. Sherman W. Myocyte replacement therapy: Skeletal myoblasts. Cell Transplant 2007;16(9):971-975. [PubMed: 18293896]

13. Sherman W, Martens TP. Catheter-based delivery of cells to the heart. Nat. Clin. Pract. Cardiovasc. Med 2006;3(Suppl 1):S57-64. [PubMed: 16501633]

14. Tran N, Li Y, Maskali F, Antunes L, Maureira P, Laurens MH, Marie PY, Karcher G, Groubatch F, Stoltz JF, Villemot JP. Short-term heart retention and distribution of intramyocardial delivered mesenchymal cells within necrotic or intact myocardium. Cell Transplant 2006;15(4):351-358. [PubMed: 16898229]

15. Yerebakan C, Kaminski A, Liebold A, Steinhoff G. Safety of intramyocardial stem cell therapy for the ischemic myocardium: Results of the Rostock trial after 5-year follow-up. Cell Transplant 2007;16(9):935-940. [PubMed: 18293892] 


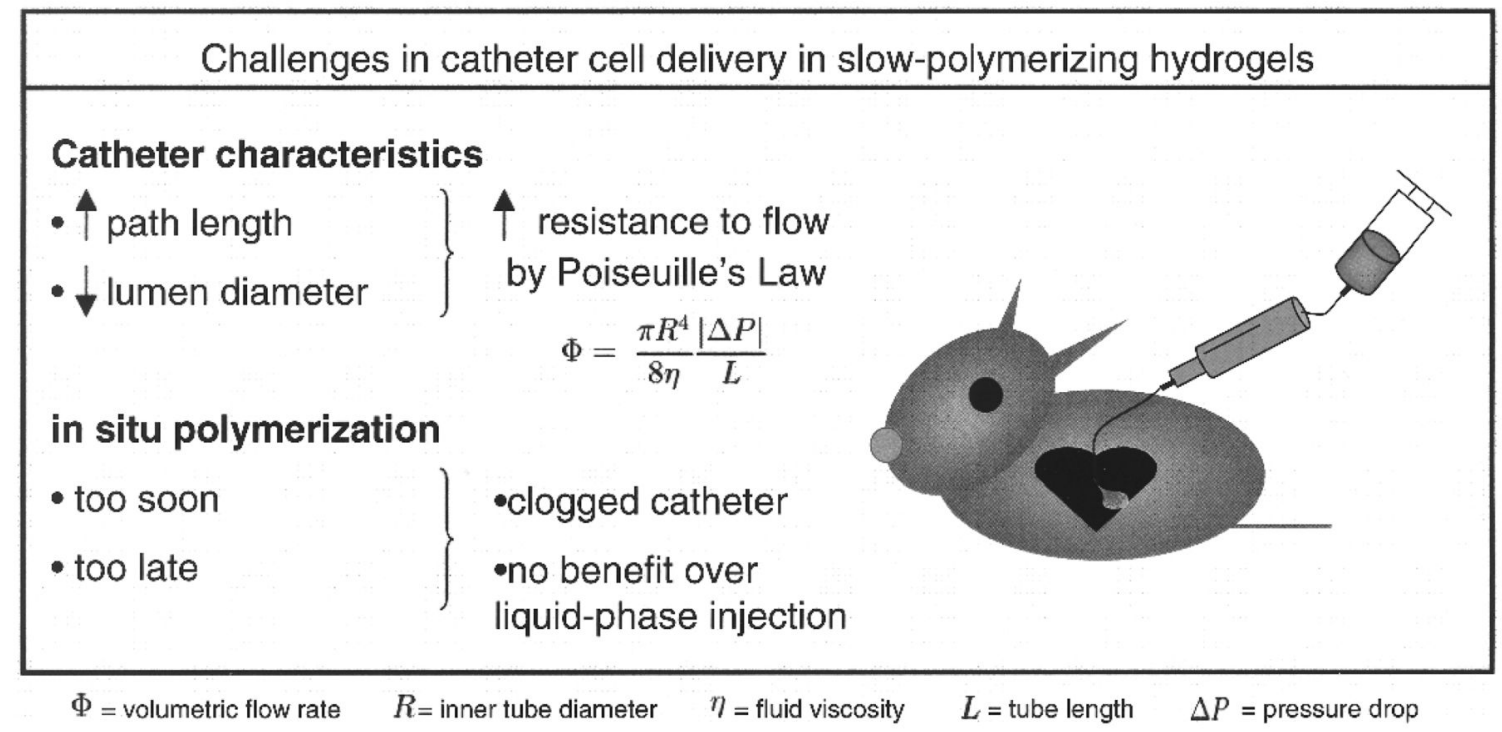

Figure 1.

Catheter-based delivery of actively polymerizing compounds is limited by increasing resistance to flow over time and requires a balance between overly rapid (clogged catheter) and overly slow (loss of cell product) kinetics. 


\section{a}

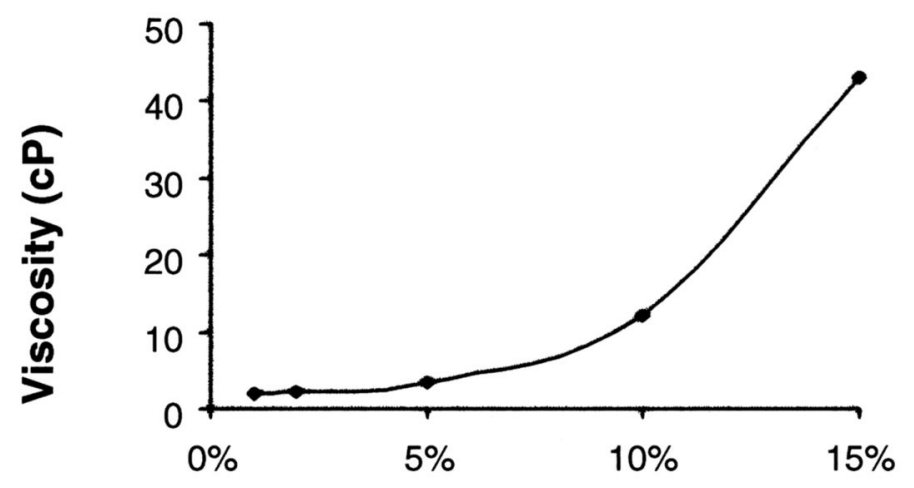

Fibrinogen Concentration \% (w/v)

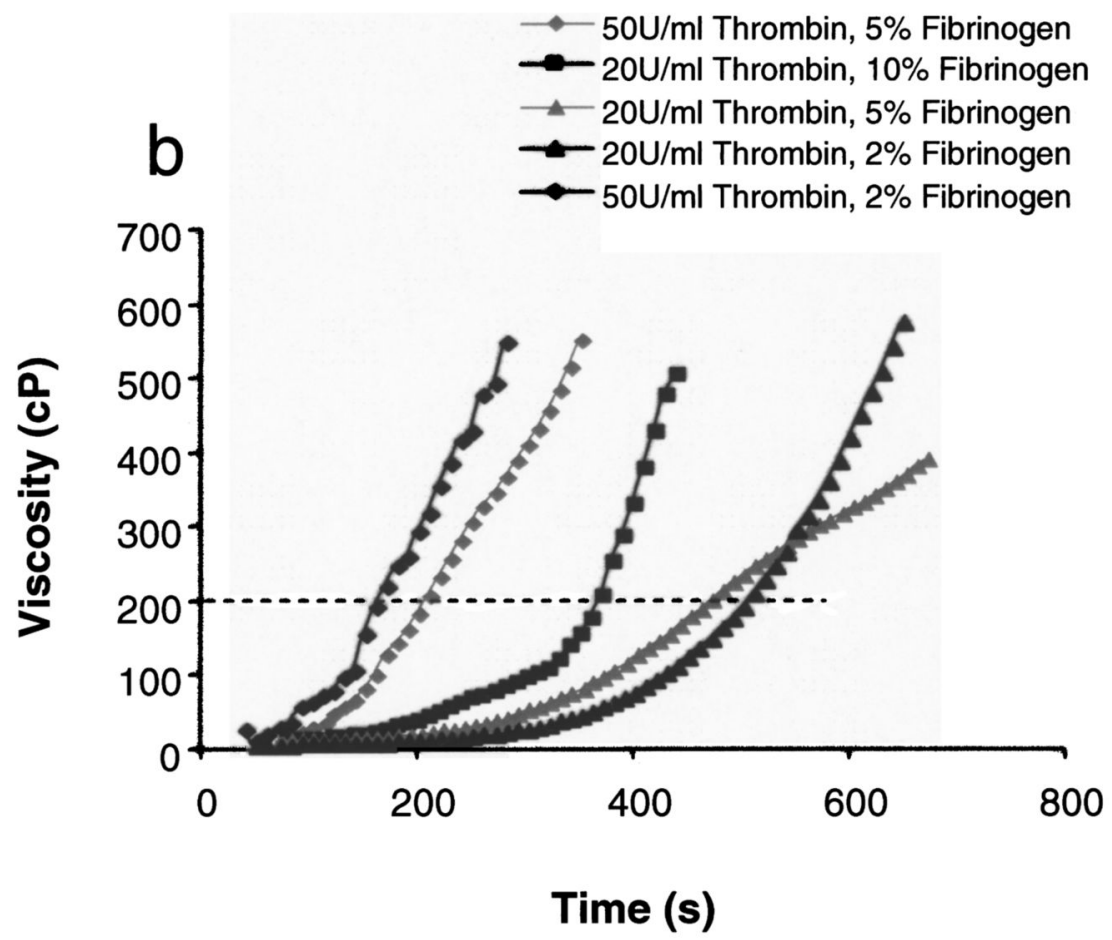

Figure 2.

(a) Fibrinogen solutions show a nonlinear increase in viscosity with increasing weight percentage. (b) By maintaining fibrinogen weight percentages below 5\% w/v and thrombin concentrations under $20 \mathrm{U} / \mathrm{ml}$, polymerization rates can be controlled to allow adequate time for percutaneous delivery. The dotted line indicates the operational upper viscosity limit of $200 \mathrm{cP}$. 

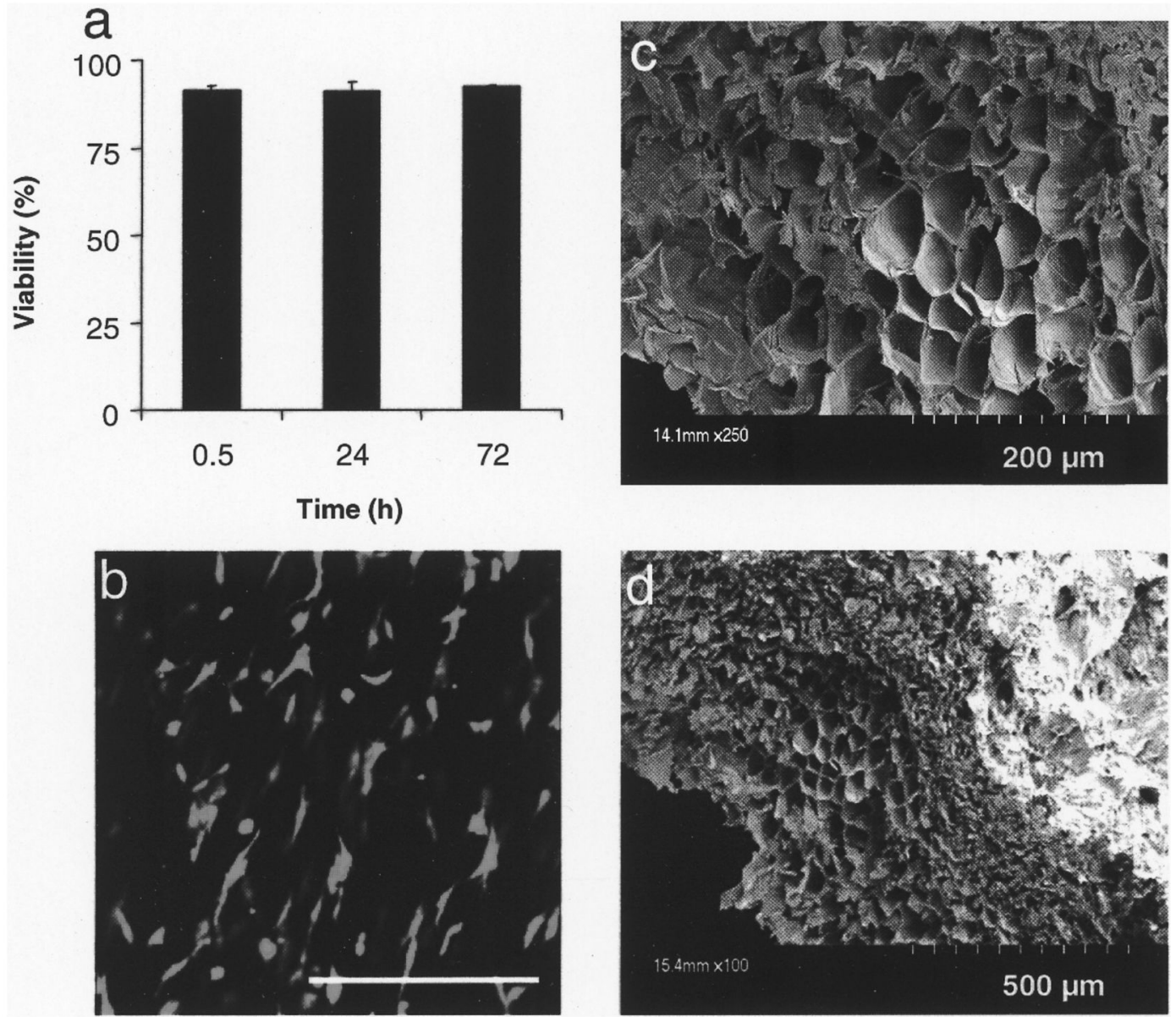

Figure 3.

(a) MSCs cultured in fibrin gels maintained excellent viability over $72 \mathrm{~h}$ of culture. (b) Livedead stain of MSCs $72 \mathrm{~h}$ after culture in a fibrin gel (living cells stain green, dead cells stain red, scale bar: $500 \mu \mathrm{m}$ ). (c, d) SEM of a $2 \%$ (w/v) fibrinogen gel polymerized with $20 \mathrm{U} / \mathrm{ml}$ of thrombin showing a heterogenous structure with pore sizes in the $20-40 \mu \mathrm{m}$ range. 

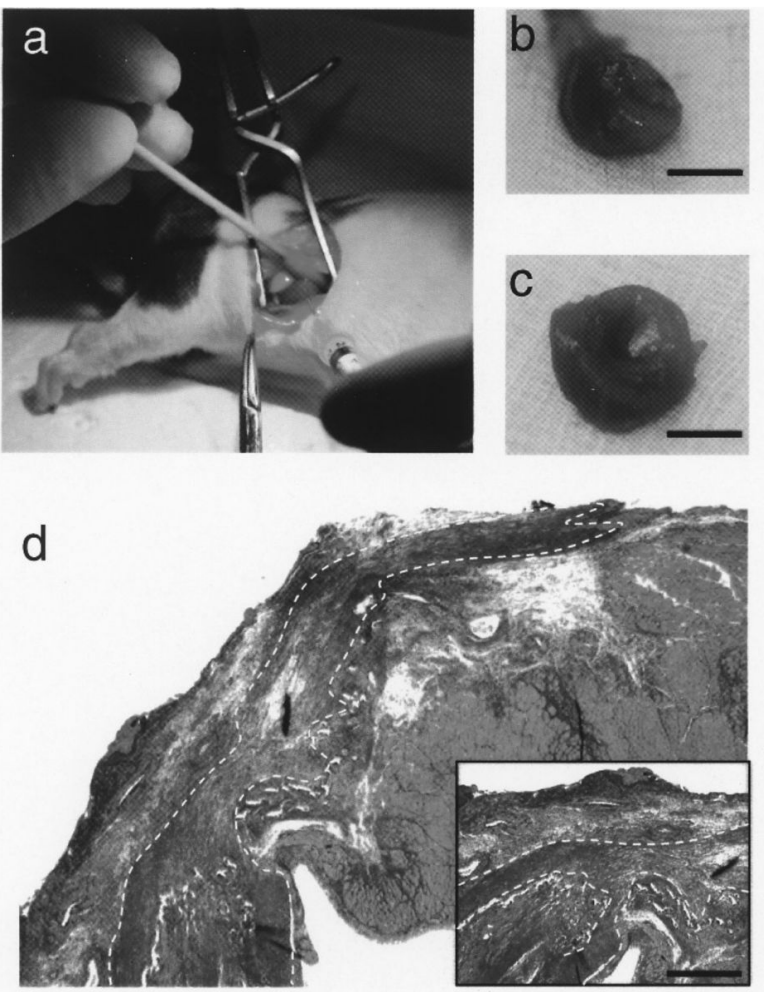

e 90min, Acute Infarct

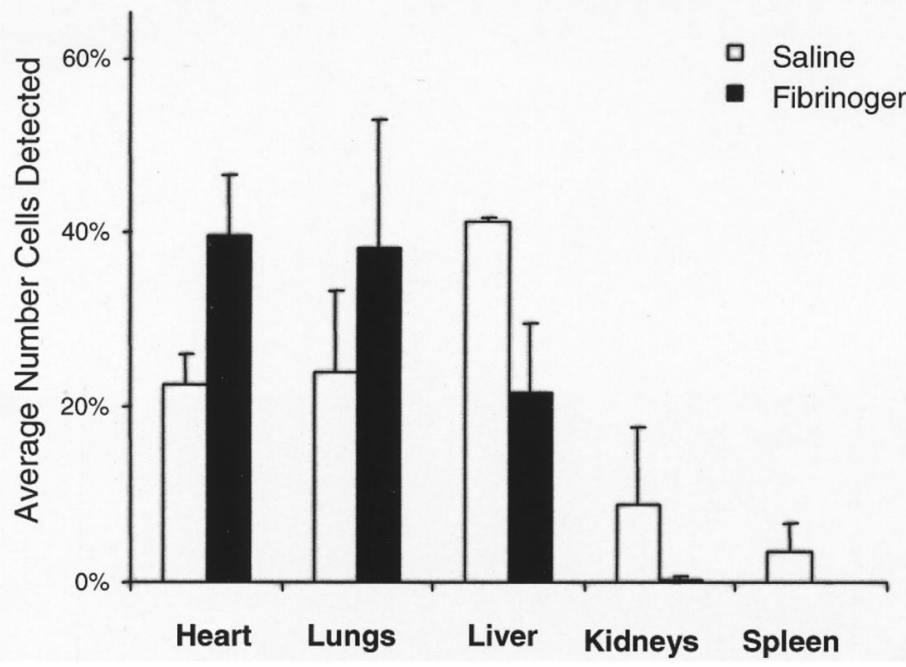

Figure 4.

(a) Intramyocardial delivery of MSCs suspended in fibrin glue results in gross retention of hydrogel (b, scale bar: $10 \mathrm{~mm}$ ) and noticeable infarct thickening (c, scale bar: $5 \mathrm{~mm}$ ) 10 days after infarction and injection. (d) Trichrome staining of a left ventricular cross section demonstrates intramural presence of injectate (scale bar: $500 \mu \mathrm{m}$ ). (e) Quantification of iridium-labeled MSCs confirms a significant increase in local cardiac retention as well as prevention of end organ redistribution when MSCs are delivered in fibrin glue (black bars) compared to saline (white bars). 


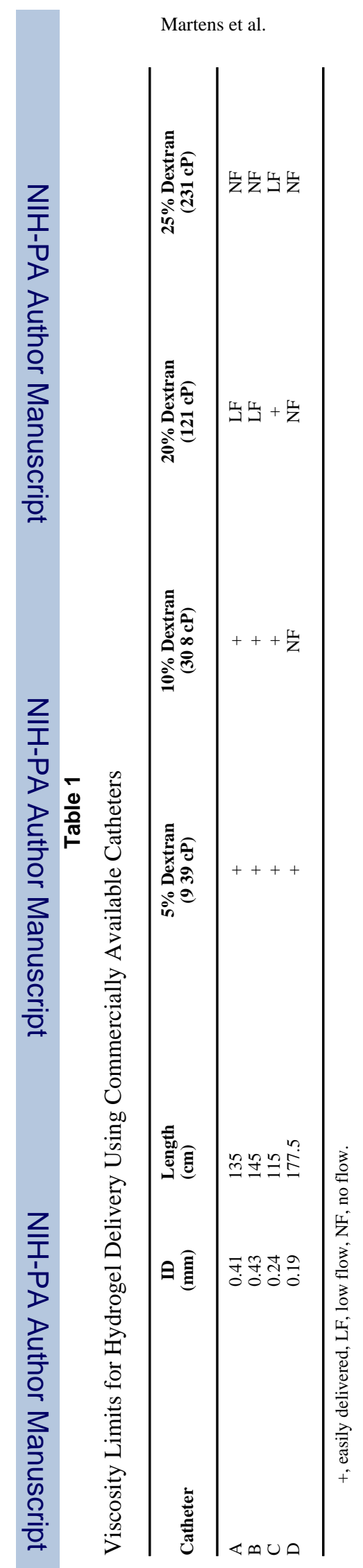

Cell Transplant. Author manuscript; available in PMC 2009 November 2. 